\title{
IMAGENS TECIDAS EM VERSO: A REPRESENTAÇÃO DO MITO DE ARIADNE NO CARMEN LXIV DE CATULO
}

\author{
ERIKA WERNER ${ }^{*}$ \\ Universidade Estadual de Campinas
}

\begin{abstract}
Resumo. Este artigo se propõe a analisar a narrativa ecfrástica relativa ao mito de Ariadne encontrada no centro do carmen 64 de Catulo e apresentar como o poeta entrelaça a narrativa acerca de Ariadne e Teseu com a celebração do casamento de Tétis e Peleu ao longo desse poema.
\end{abstract}

Palavras-chave. Catulo; Ariadne; écfrase; casamento; tecer.

D.O.I. 10.11606/issn.2358-3150.v19i1p162-180

EMbora o mais longo dos poemas supérstites de CATUlo, o CARMEN 64, seja conhecido como "Epitalâmio de Tétis e Peleu", não é a narrativa acerca da união desse casal que ocupa a maior parte dos seus versos. ${ }^{1}$ Assim como em seus outros poemas nupciais (os carmina 61 e 62), Catulo ${ }^{2}$ representa nesta composição apenas uma das etapas que tradicionalmente atribuímos à celebração de um casamento greco-romano, neste caso a chegada dos convidados à casa do noivo, não do pai da noiva, como seria esperado, e a realização do banquete nupcial. Diversamente, porém, do que vemos nesses dois outros poemas, duas outras narrativas se interpõem à representação do casamento em si. Primeiramente, a descrição da chegada dos habitantes

Doutora em Letras Clássicas pela Universidade de São Paulo/Freie Universität Berlin, com bolsa FAPESP/DAAD (2011). Atua como pesquisadora e professora colaboradora no Instituto de Estudos da Linguagem (IEL/Unicamp).

"Artigo recebido em 05.ago.2015 e aceito para publicação em 31.out.2015.

${ }^{1}$ As idéias expostas neste artigo derivam do estudo iniciado durante minha pesquisa de

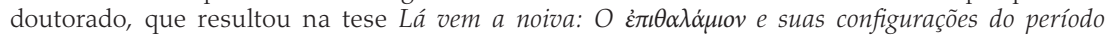
helenístico à era flaviana, defendida em janeiro de 2011 e posteriormente publicada como livro em 2014. Por esse motivo, gostaria de agradecer novamente à FAPESP, à CAPES e ao DAAD pela concessão dos auxílios à pesquisa que possibilitaram que o material bibliográfico utilizado neste texto fosse coletado.

${ }^{2}$ A principal edição dos poemas de Catulo usada neste estudo é a de Mynors (1989, 58-74). Todas as traduções apresentadas ao longo deste artigo são de minha autoria. Uma tradução integral do carmen 64 e dos demais poemas supérstites atribuídos a Catulo pode ser encontrada em Oliva Neto 1996. 
da Tessália no palácio de Peleu é interrompida pela écfrase de uma tapeçaria $^{3}$ que estaria disposta no átrio do palácio de Peleu à vista de todos que adentrariam o palácio ${ }^{4}$ e, posteriormente, a representação do banquete nupcial é interrompida pelo canto profético-nupcial que teria sido entoado pelas Parcas durante a realização do próprio banquete, ${ }^{5}$ canto este que revelaria detalhes funestos acerca da vida da progênie futura do casal, Aquiles. Os versos finais dessa composição são ainda ocupados por um epílogo, ${ }^{6}$ no qual um mundo diverso daquele que teria presenciado a união de Tétis e Peleu se descortina para sua audiência.

Ao contrário do canto das Parcas e mesmo do epílogo do poema, que podem ser associados, em maior ou menor grau, àquela que seria a narrativa central do poema, os episódios mitológicos que estariam retratados na tapeçaria aparentemente só poderiam ser relacionados à união de Tétis e Peleu a partir da temática do casamento, ainda que, de acordo com a descrição das imagens que estariam representadas na manta, a suposta união de Ariadne e Teseu tenha acabado de se desfazer e uma possível união entre Baco e Ariadne não esteja ainda determinada. Analisando-se o poema como um todo, nota-se, porém, que as imagens relativas ao mito de Ariadne se entrelaçam também a outros aspectos do poema.

Após poucas dezenas de versos, ${ }^{7}$ nos quais nos são apresentadas a ocasião em que Tétis e Peleu teriam se avistado pela primeira vez e se apaixonado, a forma como o casamento teria sido arranjado e a chegada do dia em que seriam celebradas suas núpcias, a representação dos festejos relativos a essa união é interrompida por aquela que seria a descrição de uma espécie de tapeçaria que recobriria um pulvinar nupcial disposto no átrio do palácio de Peleu no dia de suas bodas. ${ }^{8}$ A denominação puluinar, a qual designa em geral uma espécie de assento/leito onde os próprios deuses se reclinariam durante o banquete oferecido pelos mortais a eles em um lectisternium, aparentemente é utilizada aqui com um duplo sentido, já que não somente alude a esse tipo de assento destinado às divindades em tais ocasiões, prenunciando a chegada dos convidados divinos para o banquete que ocorreria posteriormente e a própria participação de Tétis neste casamento, mas parece também se referir ao costume romano de se dispor

\footnotetext{
${ }^{3}$ Catull. 64.50-264.

${ }^{4}$ Catull. 64.47-9.

${ }^{5}$ Catull. 64.323-81.

${ }^{6}$ Catull. 64.384-408.

${ }^{7}$ Catull. 64.1-49.

${ }^{8}$ Catull. 64.47-9: puluinar uero diuae geniale locatur / sedibus in mediis, Indo quod dente politum / tincta tegit roseo conchyli purpura fuco.
} 
o lectus genialis, uma espécie de leito nupcial que simbolizaria em parte a própria consumação da união, na entrada da casa por ocasião da celebração de um casamento.

De acordo com a descrição da manta apresentada pelo poeta, seriam vistas duas imagens tecidas ao longo de sua trama: em uma nos é mostrado o desespero de Ariadne ao se ver sozinha no litoral de Dia, enquanto vê Teseu partir mar adentro sem ela, em outra a aproximação de Baco/Dioniso do local, o qual se dirige com seu séquito até Ariadne, possivelmente com o intuito de se unir a ela. ${ }^{10}$ É esta segunda imagem que supostamente deveria vincular esta écfrase à narrativa principal, já que em ambos os casos seria representada a união de um deus com um mortal, mas o olhar do poeta sobre a tapeçaria apresenta a seu público um outro viés dessa história.

A tríade formada por Teseu-Ariadne-Dioniso, na qual Ariadne assumiria a posição central, representada por vezes ora somente acompanhada de Teseu, ora somente acompanhada de Dioniso, constituiria um motivo pictórico bastante popular ao longo de toda a Antigüidade, motivo este que seria encontrado em diversos suportes artísticos ao longo dos séculos. São diversas as versões do mito vistas não apenas nessas obras de arte, mas também nas fontes textuais conservadas, ${ }_{11}^{11}$ mas a configuração do mito como representada por Catulo, Teseu retornando para Atenas - Ariadne abandonada em Naxos - Dioniso se dirigindo até Ariadne, talvez se origine somente por volta dos séculos $7 / 6$ a.C., quando Teseu começa a ser alçado a herói ateniense e os mitos relacionados a seu nome passam a ser "corrigidos", de modo que sua figura é aproximada da imagem de Héracles e desvencilhada da imagem de Ariadne..$^{12}$

Catulo não revela em seu poema maiores pormenores acerca da disposição das figuras na tapeçaria, ${ }_{1}^{13}$ mas a junção desses três elementos em uma única cena ou em um único suporte não seria em princípio uma inovação, já que essa combinação pode ser ainda hoje vista em objetos de arte

\footnotetext{
${ }^{9}$ Catull., 64.50-75.

${ }^{10}$ Catull., 64.251-64.

11 Acerca dos diversos mitos relacionados à tríade "Ariadne, Teseu e Dioniso" e suas representações textuais e pictóricas, ver Hartmann 1895, 803-811; Klingner 1964, 177 ss.; Webster 1966; Derouxn 1966; Gallo 1988; Köhn 1999; Diez 2005; Armstrong 2006, 7-12, 31-70 et 187-260; Diez 2007, 15 ss.

${ }^{12}$ Acerca das modificações dos mitos associados a Teseu e sua ascensão a herói nacional ático, ver Calame 1990, 69-139 et 397-465; Walker, 1995; Mills 1997, 1-42.

${ }^{13}$ A expressão parte ex alia, "do outro lado" (Catull., 64.251), constitui a única indicação espacial fornecida pelo poeta acerca da disposição das imagens na manta, mas ela, ao invés de indicar a disposição da imagem que retrata a aproximação de Dioniso e seu cortejo, parece antes antepor essa imagem à imagem da embarcação de Teseu, provavelmente já representada ao longe, como visto ainda hoje em algumas pinturas murais encontradas nas ruínas de Pompéia.
} 
supérstites de períodos anteriores ao poeta, embora não exatamente com essa disposição dos elementos. ${ }^{14}$ Não é possível determinar se Catulo teria tido uma obra de arte em particular como modelo inicial para a écfrase presente no carmen $64{ }^{15}$ mas é possível que ele conhecesse uma ou mais representações pictóricas desse mito, já que as cenas de Ariadne abandonada por Teseu e de Dioniso/Baco encontrando Ariadne em Dia/Naxos parecem ter sido bastante populares entre os romanos, como pode ser atestado pelas pinturas murais supérstites de Pompéia. ${ }^{16}$ Segundo Köhn, duas "inovações" presentes em muitos dos painéis que retratam Ariadne abandonada seriam 1) a representação de Ariadne sozinha em primeiro plano, sem a presença de Teseu ou Dioniso a seu lado, e 2) o fato dela ser retratada desperta, avistando, chorosa, o barco de Teseu partir, detalhes que também são reproduzidos no carmen $64 \cdot{ }^{17}$ Nas cenas que retratam a aproximação de Dioniso/ Baco do local, ela costuma ser apresentada, porém, adormecida. ${ }^{18}$ Tendo em vista o material pictorial conservado, é possível que Catulo tenha escolhido duas das cenas talvez então já entre as mais populares na sua época e optado por reuni-las em uma única peça, utilizando essa popularidade a seu favor e criando um pano de fundo imediatamente identificável por seus contemporâneos para sua narração. ${ }^{19}$

A figura de Teseu aparentemente não estaria representada na tapeçaria ou teria um papel secundário, embora sua embarcação provavelmente pudesse ser avistada ao longe, como pode ser observado em afrescos supérstites de Pompéia e Herculano. Ao interligar, porém, a descrição das duas ce-

\footnotetext{
${ }^{14}$ Acerca da combinação dos motivos de "Ariadne abandonada" e "Ariadne encontrada", ver Diez 2007, 199-299.

${ }^{15}$ Para Morwood, a justaposição de cenas e histórias paralelas encontrada ao longo de todo o carmen 64 talvez refletisse uma espécie de estrutura imagética encontrada, exemplarmente, no vaso François; acerca desse modelo estrutural, ver Morwood 1999.

${ }_{16}$ Exemplos de pinturas murais retratando Ariadne sendo deixada por Teseu podem ser encontradas na Casa dei Vettii (Pompéia VI.15.1), na Casa del Meleagro (Pompéia VI.9.2; a obra se localiza atualmente no Museo Archeologico Nazionale di Napoli, número de inventário 9051) e na Casa di L. Caecilius Iucundus (Pompéia V. 1. 26; a obra também se localiza no Museo Archeologico Nazionale di Napoli, número de inventário 115396). Exemplos de Dioniso/Baco se aproximando de Ariadne, a qual se encontra adormecida, podem ser vistos em pinturas descobertas na mesma Casa dei Vetti (Pompéia VI.15.1) e na Casa del Citarista ou Domus Popidi Secundi Augustiani (Pompéia I.4.5); em ambas as representações Dioniso aparece acompanhado de mênades e sátiros.

${ }^{17}$ Ver Köhn 1999, 71: essas inovações podem ser vistas nas pinturas encontradas na Casa dei Vettii e na Casa del Meleagro. Em ambas as representações, a figura de Ariadne é amparada por um ou mais cupidos. Para uma análise das cenas em que Ariadne se encontra desperta, observando Teseu partir, e da representação do "olhar" em contexto romano, ver Elsner 2007, 28 ss.

${ }^{18}$ Gallo menciona duas pinturas murais de Pompéia, em que Ariadne se encontra desperta no momento da aproximação do deus; ver Gallo 1988, 77.

${ }^{19}$ O que provavelmente provocaria também uma espécie de tensão em seu público, já que esse deveria confrontar suas expectativas com o que lhe seria então apresentado de forma diversa daquilo que seria provavelmente esperado.
} 
nas reunidas na manta, o poeta inclui uma variada digressão em sua narrati$\mathrm{va}^{20}$ centrada sobretudo em Teseu, apresentando não apenas detalhes sobre a história pregressa de Teseu e Ariadne, mas também sobre os acontecimentos com os quais Teseu, sozinho, teria se deparado ao retornar para Atenas.

A disposição dessa narrativa paralela em meio aos festejos do casamento de Peleu e Tétis não apenas interrompe o encadeamento temporal do poema, mas também desvia a atenção da audiência do banquete nupcial para os mitos associados ao nome de Ariadne, os quais, textualmente, passam a ocupar tanto o núcleo dessa composição, quanto mais da metade dos versos de todo o poema. Embora a presença da tapeçaria recobrindo o pulvinar constitua o ensejo utilizado por Catulo para se desviar da figura dos noivos, a écfrase da manta em si representa apenas uma pequena parte na história de Ariadne relatada nos versos seguintes.

Diversamente do que seria esperado em uma écfrase desse tipo, em nenhum momento são descritos os aspectos materiais ou técnicos da peça ou mesmo sua própria origem. As poucas informações fornecidas pelo poeta são arroladas em um trecho composto por apenas sete versos, nos quais são apresentadas as riquezas que adornariam o palácio de Peleu por ocasião de suas bodas, entre as quais se encontra o pulvinar e a manta, tingida com púrpura, que o recobre:
ipsius at sedes, quacumque opulenta recessit regia, fulgenti splendent auro atque argento: candet ebur soliis; collucent pocula mensae; tota domus gaudet regali splendida gaza. puluinar uero diuae geniale locatur sedibus in mediis, Indo quod dente politum tincta tegit roseo conchyli purpura fuco. ${ }^{21}$
A residência dele, ${ }^{22}$ porém, por toda parte que o opulento palácio estende-se, resplandece com o fulgente ouro e prata.
Brilha o marfim dos tronos, refulgem os copos na mesa, toda a casa se alegra com o esplêndido tesouro real.
O pulvinar nupcial está certamente disposto para a deusa no meio da residência, o qual, ornado com uma presa hindu, a púrpura, tingida com a vermelha tinta da concha, cobre.

A natureza das imagens disposta na manta é enunciada pelo poeta no par de versos que abre a seção do poema dedicada à écfrase da manta e aos mitos associados ao nome de Ariadne, segundo os quais as figuras re-

\footnotetext{
${ }^{20}$ Catull., 64.76-250.

${ }^{21}$ Catull., 64.43-9.

${ }^{22}$ Peleu.
} 
presentadas nessa tapeçaria revelariam a seus espectadores antigas heroum uirtutes, "feitos dos heróis", ${ }^{23}$ expressão talvez empregada aqui de forma relativamente neutra. ${ }^{24}$ Embora a versão do mito difundida provavelmente a partir do final do século 6 a.C. justifique a partida de Teseu de Dia e o consequente abandono de Ariadne como uma resolução divina, de modo que as representações encontradas em vasos áticos do período apresentam muitas vezes Teseu sendo levado por Atena ou outra divindade para longe de Ariadne, e sua partida esteja relacionada à continuidade de seus feitos heróicos, não é essa, porém, a versão do mito escolhida por Catulo. As duas imagens avistadas na manta, ainda que pudessem servir como um paralelo adequado para a história de Tétis e Peleu, já que possivelmente aludiriam a um casamento entre um deus e um mortal, parecem servir apenas como pano de fundo para as conseqüências funestas das ações de Teseu, o qual, apesar de aparentemente ausente da tapeçaria, mostra-se uma figura central na digressão apresentada pelo poeta, sendo retratado de forma ambivalente e acusado sobretudo de perfídia. A mesma ambivalência também é encontrada no retrato de Aquiles cantado posteriormente pelas Parcas, cujos feitos, sangrentos e funestos para aqueles que foram mortos pelo herói, seriam igualmente reconhecidos pelas próprias mães de suas vítimas como egregias uirtutes claraque facta, ${ }^{25}$ "egrégios feitos e claras ações". ${ }^{26}$

Depois dessa breve introdução composta por apenas dois versos, apresenta-se a descrição da primeira cena, a qual retrataria o angustiante sofrimento de Ariadne ao se ver abandonada pelo amante, como ela, com os cabelos em desalinho e sem se preocupar com o decoro ou com as vestes levadas pelas ondas, ${ }^{27}$ observa Teseu partir ao longe. ${ }^{28} \mathrm{O}$ páthos de toda essa

${ }^{23}$ Catull., 64.50-1.

${ }^{24}$ Catull., 64.50-1: "haec uestis priscis hominum uariata figuris / heroum mira uirtutes indicat arte". Se considerarmos os versos correspondentes ao epílogo do carmen 64, o emprego do termo heros talvez não se refira aqui a uma espécie de "título" concedido àqueles que se destacariam por suas ações e/ou qualidades, mas sim àqueles nascidos em um determinado período mítico. Virtutes, por sua vez, provavelmente não faria referência às qualidades positivas desses indivíduos, mas designaria simplesmente suas ações, como já apontado por alguns comentadores; ver Kroll 1960, 151; Thomson 2003, 400.

${ }^{25}$ Catull. 64.348.

${ }^{26}$ Acerca das aparentes "ironias" do poema, ver Kinsey 1965. Para Stoevesandt (1994-1995), as ambiguidades identificadas principalmente nos feitos de Aquiles e uma certa ironia do poeta ao escolher uma determinada caracterização desses feitos, designando-os ainda por meio do termo "uirtutes", teriam como respaldo um ideal heróico homérico, encontrado sobretudo na Ilíada.

${ }^{27}$ Formando um contraponto a essa imagem, as Nereidas também são retratadas com a parte superior do corpo nu (Catull., 64.12-18). Acerca da imagem das Nereidas neste poema, ver Cairns 1984.

${ }^{28}$ Catull., 64.52-67. Para Fitzgerald e Elsner, a imagem e o ato de "olhar" seriam destacados ao longo de todo o poema e sua presença apareceria de forma mais enfática na seção do poema dedicada a Ariadne; ver Fitzgerald 1995; Elsner 2007, 21-5. 
cena é intensificado pela disposição, no fim dessa passagem, de uma apóstrofe do poeta a Teseu, ${ }^{29}$ como que recordando o herói dos laços que uniam Ariadne a ele, e de uma exclamatio, por meio da qual se recorda ao público como Vênus Ericina ${ }^{30}$ é capaz de trazer sofrimentos aos mortais atingidos pela paixão. ${ }^{31}$ Essa exclamatio não apenas enuncia textualmente as conseqüências negativas da paixão e aponta a deusa como responsável pelo sofrimento de Ariadne, já que Ariadne teria se apaixonado por Teseu sob seus encantos, mas também introduz os principais elementos que serão encontrados na digressão do poeta acerca desse mito, lembrando como o trágico destino de Ariadne se inicia quando Teseu aporta no litoral de Creta. ${ }^{32}$

À descrição da primeira imagem da manta segue-se uma longa digressão (76-250), a qual nos apresenta outros elementos do mito relativo a Teseu e Ariadne que não estão representados na tapeçaria e se afasta em grande medida da imagem que teria sido vista pelo público que adentrara o palácio de Peleu, digressão esta que pode ser dividida em quatro partes. A primeira $^{33} \mathrm{e}$ a segunda ${ }^{34}$ partes tratam dos acontecimentos que antecedem $\mathrm{o}$ abandono de Ariadne em Dia, a terceira ${ }^{35}$ apresenta o lamento de Ariadne ao se ver abandonada na ilha e a quarta e última parte ${ }^{36}$ revela o destino com o qual se depara Teseu ao retornar a Atenas.

A primeira dessas partes ${ }^{37}$ é dedicada ao intervalo temporal que vai da decisão de Teseu de se oferecer como vítima ao Minotauro no lugar do grupo de jovens atenienses destinados ao sacrifício como contrapartida à morte de Andrógeo, filho de Minos, ${ }^{38}$ até a saída do herói do labirinto após ter matado o monstro. ${ }^{39} \mathrm{O}$ núcleo dessa passagem é ocupado, porém, como anunciado pela exclamatio presente nos versos anteriores, pela descrição de como a paixão por Teseu toma todo o corpo de Ariadne, levando-a a ajudá-lo a derrotar seu meio-irmão, o Minotauro. ${ }^{40}$ No centro dessa descrição, destacam-se a imagem da chama da paixão percorrendo todo o corpo da

${ }^{29}$ Catull., 64. 68-70.

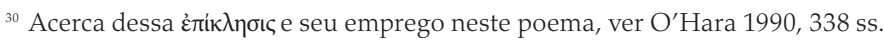

${ }^{31}$ Catull., 64.71-5.

${ }_{32}$ Catull., 64.71-5: a misera, assiduis quam luctibus externauit / spinosas Erycina, serens in pectore curas, / illa tempestate, ferox quo ex tempore Theseus / egressus curuis e litoribus Piraei / attigit iniusti regis Gortynia templa.

${ }^{33}$ Catull., 64.76-115.

${ }^{34}$ Catull., 64.116-23.

${ }^{35}$ Catull., 64.124-201.

${ }^{36}$ Catull., 64.202-48.

${ }^{37}$ Catull., 64.76-115.

${ }^{38}$ Catull., 64.76-85.

${ }^{39}$ Catull., 64.105-15

${ }^{40}$ Catull., 64.86-104. 
jovem e penetrando até sua medula ${ }^{41}$ e uma apóstrofe do poeta a Amor, atribuindo agora a ele a origem da paixão que toma Ariadne. ${ }^{42}$ Como contraponto à paixão de Ariadne estariam os próprios feitos de Teseu, o qual teria optado por enfrentar o Minotauro no lugar de muitos conterrâneos, sabendo que isso lhe traria a glória ou a morte ${ }^{43}$; com a ajuda de Ariadne, a qual, por amor a ele, trai sua família e participa, indiretamente, do assassinato de seu meio-irmão, ele obtém a glória, não a morte. ${ }^{44}$

A segunda parte da digressão ${ }^{45}$ é composta por uma longa praeteritio, por meio da qual o poeta lista diversos acontecimentos que ele não incluirá em sua narrativa: a partida de Ariadne de Creta, a despedida de sua mãe e de sua irmã, o trajeto da embarcação até o litoral de Dia, a partida de Teseu, sozinho, da ilha em direção a Atenas. O motivo pelo qual o poeta não teria se dedicado mais detalhadamente a esses temas em sua narrativa encontrase, porém, já no verso inicial desta seção, ${ }^{46}$ no qual ele indica que se voltar para esses tópicos seria se afastar a primo [...] carmine, "do canto inicial". Embora ele opte por não desenvolver esses subtemas, sua breve menção já é suficiente para recordar ao público os acontecimentos situados entre a morte do Minotauro e o abandono de Ariadne e mostrar como sua escolha, deixar sua família para trás e seguir Teseu, coloca-se contra a noção romana de pietas, a obrigação e o respeito que Ariadne deveria apresentar em relação não apenas aos deuses, mas também em relação a sua família. ${ }^{47} \mathrm{O}$ uso da expressão a primo digressus carmine ${ }^{48}$ pode ser contrastado ainda com a estrutura do poema como um todo, já que o próprio poeta não se atém à narrativa referente ao casamento de Peleu e Tétis ao longo do poema, entremeando essa narrativa com relatos paralelos acerca da Ariadne e Teseu.

A terceira parte da digressão ${ }^{49}$ retorna ao "canto inicial", retomando a imagem de Ariadne em Dia. Esta seção do poema é quase totalmente

${ }^{41}$ Catull., 64.91-3: non prius ex illo flagrantia declinauit / lumina, quam cuncto concepit corpore flammam / funditus atque imis exarsit tota medullis.

${ }^{42}$ Catull., 64.94-8: heu misere exagitans immiti corde furores / sancte puer, curis hominum qui gaudia misces, / quaeque regis Golgos quaeque Idalium frondosum, / qualibus incensam iactastis mente puellam / fluctibus, in flauo saepe hospite suspirantem!

${ }^{43}$ Catull., 64.101-2: cum saeuum cupiens contra contendere monstrum / aut mortem appeteret Theseus aut praemia laudis!

${ }^{44}$ Catull., 64.112-15. Para Knopp, o principal tema do poema seria o conflito entre amores e uirtutes, conflito que se revela sobretudo nas narrativas acerca de Ariadne e Teseu; ver Knopp 1976.

${ }^{45}$ Catull., 64.116-23.

${ }^{46}$ Catull., 64.116-17: sed quid ego a primo digressus carmine plura / commemorem [...].

${ }^{47}$ Acerca do conceito romano de pietas e de sua abrangência, ver C. Koch (1941). RE, 20, s.v. Pietas, c. 1221-1232; TLL, 10.1,14, s.u. "Pietas, -atis", cc. 2086-2105. Para um panorama acerca das idéias morais e políticas romanas, ver também Pereira 1980, 317-428.

${ }^{48}$ Catull., 64.116.

${ }^{49}$ Catull., 64.124-201. 
ocupada pela fala emitida pela jovem ao se ver abandonada, a qual é precedida por uma breve introdução, ${ }^{50}$ composta por quatro pares de versos, nos quais são descritas as reações de Ariadne ao se dar conta de sua situação. De acordo com essa descrição, primeiramente ela teria gritado, ${ }^{51}$ depois se dirigido aos montes para tentar avistar Teseu de seus cumes, ${ }^{52}$ em seguida tentado adentrar $0 \operatorname{mar}^{53} \mathrm{e}$, por fim, provavelmente percebendo que Teseu havia partido sem volta e ela nunca conseguiria alcançá-lo, ela, em meio a soluços, dirige a ele uma fala, ${ }^{54}$ a qual seria reproduzida pelo poeta logo a seguir, lamentando seu próprio destino.

O lamento de Ariadne propriamente dito ${ }^{55}$ é composto por 70 versos e pode ser dividido em duas partes centrais, a primeira delas endereçada a Teseu, ${ }^{56}$ a quem a jovem acusa, por tê-la "esquecido" em Dia, de perfídia e perjúrio, ${ }^{57} \mathrm{e}$ a segunda endereçada aos deuses, ${ }^{58}$ a quem ela se lamenta de seu destino e clama por vingança. As recriminações contra Teseu se iniciam com a atribuição a ele do adjetivo perfidus, "pérfido", 59 empregado em uma

${ }^{50}$ Catull., 64.124-31.

${ }^{51}$ Catull., 64.124-5: saepe illam perhibent ardenti corde furentem / clarisonas imo fudisse e pectore uoces $[\ldots]$

${ }^{52}$ Catull., 64.126-7: ac tum praeruptos tristem conscendere montes, / unde aciem <in > pelagi uastos protenderet aestus [...]

${ }^{53}$ Catull., 64.128-9: tum tremuli salis aduersas procurrere in undas / mollia nudatae tollentem tegmina surae [...]

${ }^{54}$ Catull., 64.130-1: atque haec extremis maestam dixisse querellis, / frigidulos udo singultus ore cientem $[\ldots]$

${ }^{55}$ Catull., 64.132-201.

${ }^{56}$ Catull., 64.132-63.

${ }^{57}$ Como já indicado por diversos comentadores, um dos principais modelos para essa primeira parte do lamento de Ariadne parece ser o lamento de Medéia na tragédia homônima de Eurípides (E., Med. 465-519) e nos Argonautica de Apolônio Ródio (A. R., 4.355-90). Acerca dos diversos mitos associados ao nome de Medeia, ver A. Lesky (1931). RE, s.v. Medeia, c. 29-65; A. Arcellaschi 1990, 13-36; Mastronarde 2006, 44-57. Acerca dos mitos associados às figuras de Jasão e Medéia ao longo da Antigüidade, ver também Moreau 1994. Acerca das diversas esferas utilizadas por Eurípides em sua construção da imagem de Medeia, ver Boedeker 1997. Para Trimble (2009), toda a seção referente a Ariadne poderia ser vista como uma espécie de tragédia, a qual seria emoldurada por uma narrativa épica. Para Auhagen (2000), a obra de Ênio também teria influenciado a construção desse monólogo. Acerca das semelhanças entre os mitos relacionados a Jasão e Teseu, mitos que talvez representassem a passagem do jovem homem para a idade adulta, ver também Hunter 1988, 449 ss. Outra narrativa que apresenta paralelos com história de Ariadne e Teseu é o canto IV da Eneida de Vergílio, onde é representada a história de Dido e Enéias; acerca dessa narrativa, ver Pease 1967, 3-79; Williams 1968, 374-87; Horsfall 1990; Rudd 1990; Clausen 2002, 75-113; Eidinow 2003. Acerca de algumas semelhanças entre o mito de Ariadne e Teseu contado por Catulo no carmen 64 e a representação do amor entre Dido e Enéias na Eneida de Vergílio, ver também Armstrong 2006, 56-61. Acerca da influência da imagem de Jasão e Medéia encontrada nos Argonautica sobre a representação de Dido e Ulisses na Eneida, ver também Rodrigues Jr. 2005, 78 ss.

${ }^{58}$ Catull., 64.169-201.

${ }^{59}$ Catull., 64.132.

Let. Cláss., São Paulo, v.19, n. 1, p.162-180, 2015 
construção epanaléptica ${ }^{60}$ que parece enfatizar o valor negativo do adjetivo, acusando-o duplamente por tê-la levado de Creta sem o consentimento de seu pai, o que impossibilitaria o reconhecimento da união como legítima perante sua família, e por tê-la abandonado, logo em seguida, sozinha em Dia, ignorando os laços que deveriam uni-los. O sentido do adjetivo perfidus, reiterado por Ariadne no lamento que ela dirige aos deuses, é intensificado pelas enunciações presentes nos versos seguintes, por meio das quais a jovem o acusa de desrespeitar não apenas as promessas de casamento feitas a ela, mas também os juramentos testemunhados pelos próprios deuses. $\mathrm{O}$ efeito dramático dessas acusações atinge seu auge com o emprego de uma exortação, ${ }^{61}$ na qual Ariadne adverte todas as mulheres a nunca acreditarem nos juramentos e promessas vindas de um homem, transformando seu lamento particular em uma acusação contra todos os representantes do sexo masculino e, indiretamente, também contra a instituição do casamento.

Os versos que concluem a parte da fala endereçada a Teseu ${ }^{62}$ descrevem as conseqüências da paixão para Ariadne. ${ }^{63}$ Em um tom ambíguo, ao mesmo tempo ela admite sua culpa, por ter preferido ajudar Teseu a vê-lo morto, o que culminou na morte de seu irmão e em sua separação da própria família, mostrando ciência dos próprios feitos e da violação da pietas, mas também se apresenta como incapaz de controlar seu próprio destino, apresentando a impossibilidade de se desvincular do herói e a admissão de que ela, por causa dessa paixão, estaria disposta a se rebaixar ainda mais, ignorando sua origem real e colocando-se na posição hipotética de cativa, por ele.

Os versos endereçados a Teseu ${ }^{64}$ e aos deuses ${ }^{65}$ são separados por um breve interlúdio, ${ }^{66}$ no qual Ariadne aparentemente reconheceria a ineficácia de endereçar queixumes e acusações ao amante ausente, servindo como transição para a segunda parte da fala. A seção endereçada aos deuses ${ }^{67}$ se inicia com Ariadne se dirigindo a Fortuna e a Júpiter. A primeira seria

${ }^{60}$ Catull., 64.132-3: sicine me patriis auectam, perfide, ab aris, / perfide, deserto liquisti in litore, Theseu?

${ }^{61}$ Catull., 64.143-8.

${ }^{62}$ Catull., 64.149-63.

${ }^{63}$ É a paixão também, incitada por Afrodite e Eros, que leva Medéia a trair sua família e sua pátria em nome do amor por Jasão. Acerca da presença do imaginário erótico ao longo dos Argonautica, ver Rodrigues Jr. 2005, 96 ss.. Para DeBrohun (1999), os diversos níveis de confusão identificados nos versos 149-57 prefigurariam as relações familiares não-naturais mencionadas no epílogo e a própria tensão entre as narrativas presentes neste poema e aquelas encontradas em seus predecessores.

${ }^{64}$ Catull., 64.132-63.

${ }^{65}$ Catull., 64.169-201.

${ }^{66}$ Catull., 64.164-8.

${ }^{67}$ Catull., 64.169-201.

Let. Cláss., São Paulo, v.19, n. 1, p.162-180, 2015 
responsável pelos caminhos que seu destino tomara e ainda iria tomar, a qual ela acusa, porém, de tapar os ouvidos a suas súplicas. ${ }^{68}$ Ao segundo ela roga, intitulando-o omnipotens, "onipotente", 69 que o destino de Teseu, a quem ela qualifica novamente como perfidus, ${ }^{70}$ tivesse sido outro e que ele nunca tivesse chegado ao reino de Minos, ${ }^{71}$ rogo que ela sabe, porém, que nunca poderá ser atendido.

Nos versos seguintes, ${ }^{72}$ Ariadne se reconhece na posição de noiva/ esposa abandonada, a qual, segundo alguns costumes gregos e romanos, ${ }^{73}$ não seria em princípio independente, mas deveria retornar para a casa de seu pai ou tutor, caso o casamento tivesse sido desfeito. ${ }^{74}$ Nenhuma das opções normalmente existentes, permanecer sob a tutela do pai ou do esposo, mostra-se, porém, exeqüível aqui, não apenas porque Ariadne partira com Teseu sem a permissão de seu pai, após ter tido participação na morte do próprio irmão, e porque Teseu a abandonara sozinha em Dia, mas também porque não haveria para ela modos de deixar a ilha.

A seu abandono, prova da perfídia e do perjúrio de seu amante, associam-se então o reconhecimento de seu isolamento e de uma iminente morte ${ }^{75}$ transformando a paixão que ocupara seu peito em desejo de vingança, de modo que a jovem termina sua fala dirigindo uma súplica às Eumênides, ${ }^{76}$ às quais ela clama que o esquecimento de Teseu seja vingado com esquecimento. ${ }^{77}$ É por meio do emprego do adjetivo immemor, "esquecido",

${ }^{68}$ Catull., 64.169-70.

${ }^{69}$ Catull., 64.171.

${ }^{70}$ Catull., 64.174

${ }^{71}$ Catull., 64.171-6.

${ }^{72}$ Catull., 64.177-86.

${ }_{73}$ Acerca dos costumes matrimoniais gregos, ver J. Heckenbach (1913). RE, 8, s.v. Hochzeit, c. 2129-33; Erdmann 1934; Wolff 1944; Gernet 1953; Finley 1955; Lacey 1966; Vernant 1992; Snodgrass 1974, 115 ss; Morris 1986; Contiades-Tsitsoni 1991; Perysinakis 1991; Oakley et Sinos 1993, 1-47; Oswald 1998; Bouvier 2002. Acerca dos costumes matrimoniais romanos, ver Treggiari 1991, 13-36; Hersch 2010, 15 ss.

${ }^{74}$ Para Ariadne, sua ligação amorosa com Teseu constituiria um casamento: Catull., 64.141: conubia laeta, optatos hymenaeos; 158: nostra conubia; 182: conniugis. Para Curran, a gloriosa fertilidade de Tétis e Peleu se oporia ao "infertilidade" da união de Ariadne e Teseu no carmen 64, de modo que Ariadne estaria se referindo de forma amargamente sarcástica a sua união com Teseu por meio desse vocabulário e Catulo, também de maneira irônica, associaria a ela imagens referentes à maternidade, embora as únicas coisas geradas por ela sejam a paixão por Teseu e seu lamento posterior; ver Curran 1969, 175. Para Konstan (1977, 75-7), Ariadne não apenas se refere a sua união com Teseu como sendo um "casamento", mas ela também seria retratada por meio de elementos que remeteriam a um epitalâmio.

${ }^{75}$ Catull., 64.186-7: nulla fugae ratio, nulla spes: omnia muta, / omnia sunt deserta, ostentant omnia letum.

${ }^{76}$ Catull., 64.188-201.

${ }_{77}$ Catull., 64.200-1: sed quali solam Theseus me mente reliquit, / tali mente, deae, funestet seque suosque. 
que o poeta apresenta o motivo do abandono de Ariadne em sua versão do mito, reiterando essa acusação contra Teseu em todas as subdivisões narrativas correspondentes à história de Ariadne e Teseu, com exceção da primeira parte da digressão, dedicada aos acontecimentos ocorridos entre a chegada de Teseu em Creta e a morte do Minotauro, e transformando o esquecimento na própria punição do herói. ${ }^{78}$

A última parte da digressão relativa à história de Teseu e Ariadne ${ }^{79}$ relata como seu esquecimento seria funesto não apenas para Ariadne, mas também para o próprio herói. Essa subdivisão do poema se inicia com a anuência divina à súplica da jovem, ${ }^{80}$ anuência que seria manifestada não apenas pelo aceno de cabeça de Júpiter, deus que consentiria igualmente na união de Peleu e Tétis, mas também pela reverberação desse movimento em três das partes que comporiam o mundo: a terra, o céu e o mar. ${ }^{81}$ Em seguida, a atenção se volta finalmente para Teseu, narrando-se como o olvido toma a mente do herói no momento em que ele aproxima de Atenas, ${ }^{82}$ o que culmina no suicídio de seu próprio pai, Egeu. ${ }^{83}$ No momento em que ele adentra a casa paterna, um sofrimento semelhante àquele que ele causara a Ariadne se instala em seu peito e ele se reconhece culpado por essa morte, ${ }^{84}$ o que não ocorre em relação ao abandono de Ariadne, concretizando a vingança clamada pela jovem e anuída pelos deuses.

A descrição dos males causados pelo esquecimento de Teseu a si próprio é interrompida, porém, por mais uma digressão, a qual, por meio sobretudo da representação da fala que seu pai teria lhe dirigido antes dele partir para Creta, ${ }^{85}$ apresenta as promessas que Teseu teria feito a ele e que, não cumpridas, assim como as próprias promessas que o herói teria feito a Ariadne, teriam sido a causa da morte paterna. Embora Teseu seja uma das

\footnotetext{
${ }^{78}$ Catull., 64.58, 123, 135 et 248. Immemor e perfidus são também as acusações que Catulo dirige a seu amigo Alfeno em outra de sua composições (Catull., 30), acusações que, assim espera o poeta, também deveriam ser punidas pelos deuses, como visto no carmen 64 .

${ }^{79}$ Catull., 64.202-48.

${ }^{80}$ Catull., 64.202-6.

${ }^{81}$ Catull., 64.205-6: "quo motu tellus atque horrida contremuerunt / aequora concussitque micantia sidera mundus.' A súplica de Ariadne se mostra mais eficaz que a prece de Egeu, já que esse teria pedido anteriormente a Atena que Teseu não se esquecesse das promessas feitas a ele, seu pai (Catull., 64.228-32): "quod tibi si sancti concesserit incola Itoni, / quae nostrum genus ac sedes defendere Erecthei / annuit, ut tauri respergas sanguine dextram, / tum uero facito ut memori tibi condita corde / haec uigeant mandata, nec ulla oblitteret aetas."

${ }^{82}$ Catull., 64.207-11; 238-40.

${ }^{83}$ Catull., 64.241-5.

${ }^{84}$ Catull., 64.246-8: "sic funesta domus ingressus tecta paterna / morte ferox Theseus, qualem Minoidi luctum / obtulerat mente immemori, talem ipse recepit." Acerca de alguns paralelos entre a descrição de Ariadne e de Egeu, ver Putnam 1961, 185 ss.

${ }^{85}$ Catull., 64.212-37.
} 
principais personagens nessas digressões expostas por Catulo, em nenhum momento nos é apresentada sua versão da história e mesmo nesta cena, em que a participação de Ariadne é indireta, o poeta prefere reproduzir uma fala atribuída a seu pai, Egeu, a dar a palavra ao herói.

Diversamente da participação de Ariadne na morte do meio-irmão e no abandono de sua própria família, a "perfídia" de Teseu em relação ao acordo que ele teria firmado com Egeu e sua participação indireta na morte de seu pai é, porém, determinada por uma decisão divina. O modo afetuoso empregado por Egeu para se referir a Teseu em sua fala, ${ }^{86}$ assim como a representação do suicídio paterno como resposta à suposta morte do filho ${ }^{87} \mathrm{e}$ a menção ao sofrimento do herói ao se deparar com a morte de seu pai ${ }^{88}$ parecem ter como objetivo tanto apresentar a grandeza da punição que Teseu teria recebido por seus atos, punição que seria proporcional à crueldade desses atos, quanto enfatizar a estreiteza dos laços existentes entre pai e filho. A falta de pietas de Ariadne perante sua família se contrapõe diretamente ao vínculo existente entre Teseu e Egeu, mas os atos de ambos, sejam eles motivados pela paixão (traindo sua própria família), sejam eles motivados pelo esquecimento (traindo suas próprias promessas), trariam conseqüências não apenas para suas famílias, mas também para suas pátrias. Essa última parte se encerra com a retomada da primeira imagem representada na manta, em que se veria Ariadne, aflita, no litoral de Dia, observando Teseu partir ao longe, imagem que conduz a atenção da audiência de volta à tapeçaria. ${ }^{89}$

A écfrase da segunda cena, ${ }^{90}$ aparentemente tecida em outra parte da manta, ${ }^{91}$ inicia-se com uma apóstrofe a Ariadne, ${ }^{92}$ na qual se descreve a aproximação de Iaco/Baco, acompanhado de um séquito composto de sátiros, silenos e bacantes, como também visto nas pinturas murais romanas supérstites, e possivelmente se dirigindo para a ilha com o intuito de desposá-la, embora Ariadne tenha se reconhecido culpada em relação aos crimes contra sua própria família. ${ }^{93} \mathrm{~A}$ écfrase é concluída com a descrição do

${ }^{86}$ Catull., 64.215 sqq.

${ }^{87}$ Catull., 64.241-5.

${ }^{88}$ Catull., 64.246-8.

${ }^{89}$ Catull., 64.249-50.

${ }^{90}$ Catull., 64.251-64.

${ }^{91}$ Catull., 64.252: parte ex alia.

${ }_{92}$ Catull., 64.251-3.

${ }_{93}$ Para Wiseman $(1977,1978)$, a intenção de Dioniso poderia ser identificada como rapto, não casamento, embora ele acredite que não seja possível identificar a qual versão do mito Catulo esteja se referindo. Contra Wiseman e a sugestão de rapto que estaria presente nessa passagem, ver Giangrande 1977, Forsyth 1980. Embora a representação do cortejo nupcial de Ariadne e Dioniso já seja encontrada em Pompéia, esse motivo parece tornar-se realmente popular somente a partir do século II d.C., aparecendo sobretudo na arte sepulcral; ver Köhn 1999, 38-43; 75 ss.). 
cortejo de bacantes, ${ }^{94}$ na qual se destacam tantos os exóticos adereços portados por elas, ${ }^{95}$ quanto seus variados instrumentos musicais, cujas distintas sonoridades são enfatizadas textualmente por assonâncias e aliterações, ${ }^{96}$ conferindo um curioso colorido a essa cena. Diversamente da primeira cena, cujos acontecimentos pregressos e posteriores relativos ao mito são apresentados em diversas digressões, nada é dito aqui, ao menos nos versos supérstites, acerca da união posterior de Ariadne e Baco ou sobre o que teria motivado o deus a se dirigir a ilha, nem sobre a disposição dessa imagem em relação à primeira cena. ${ }^{97}$

Tendo sido encerrada a descrição das cenas tecidas na manta, fim que é delimitado por dois versos, ${ }^{98}$ os quais remetem textualmente aos versos que marcam o início da écfrase ${ }^{99}$ e atraem a atenção da audiência de volta ao átrio do palácio de Peleu, onde estaria disposto o pulvinar recoberto pela manta, a narrativa referente às bodas de Tétis e Peleu é retomada. ${ }^{100}$

Não é apenas por sua breve extensão ou pela ausência de informações, se a compararmos com a descrição da cena relativa a Ariadne abandonada e às digressões que a seguem, que a cena referente à chegada de Baco em Dia parece ser negligenciada pelo poeta nesta composição. A omissão de referências diretas a uma possível união entre o deus e Ariadne e o contraste com os diversos indícios textuais que atrelam o casal Teseu-Ariadne às outras partes do poema também contribuem para que o mito relativo a Baco-Ariadne se distancie em grande medida da narrativa principal e o mito relativo a Teseu-Ariadne ganhe posição de destaque.

${ }^{94}$ Catull., 64.254-64.

${ }_{95}$ Catull., 64.256-60: harum pars tecta quatiebant cuspide thyrsos, / pars e diuulso iactabant membra iuuenco, / pars sese tortis serpentibus incingebant, / pars obscura cauis celebrabant orgia cistis, / orgia quae frustra cupiunt audire profani.

${ }^{96}$ Catull., 64.261-4: "plangebant aliae proceris tympana palmis, / aut tereti tenuis tinnitus aere ciebant; / multis raucisonos efflabant cornua bombos / barbaraque horribili stridebat tibia cantu." Epanalepses e assonâncias também marcam textualmente, de maneira um pouco menos enfática, os versos dedicados à descrição dos objetos portados pelas bacantes, destacando-se, em primeiro plano, a anáfora de pars na posição inicial dos quatro primeiros versos (com exceção do verso 256, onde pars ocupa a segunda posição do verso).

${ }^{97}$ De acordo com as representações pictóricas conhecidas desse mito, Ariadne se encontraria geralmente adormecida durante a aproximação do deus. Não é possível se determinar se as imagens deveriam estar retratadas de modo independente ao longo da manta e haveria duas diferentes representações da figura de Ariadne visíveis em sua trama ou se as imagens estariam interligadas por uma única figura de Ariadne tomada pelo desespero e ignorante da aproximação de Baco.

${ }_{98}$ Catull., 64.265-6: talibus amplifice uestis decorata figuris / puluinar complexa suo uelabat amictu.

${ }_{99}$ Catull., 64.50-1: haec uestis priscis hominum uariata figuris / heroum mira uirtutes indicat arte.

${ }_{100}$ Catull., 64.267-383. 
As narrativas acerca de Teseu e Ariadne presentes neste poema encontram paralelos sobretudo nas passagens referentes à caracterização das Parcas e ao canto entoado por elas. O futuro de Aquiles profetizado nesse canto ${ }^{101}$ é apresentado de maneira tão ambígua quanto o retrato de Teseu nas digressões acerca da manta disposta sobre o pulvinar e, na súplica de Ariadne dirigida às Eumênides, destaca-se a atribuição do adjetivo uerae ${ }^{102}$ ao lamento de Ariadne em si [querellae], aproximando essa súplica do próprio canto entoado pelas Parcas, o qual é caracterizado pelo poeta não apenas como ueridicos, ${ }^{103}$ mas também como livre de perfídia, ${ }^{104}$ justamente uma das acusações da jovem contra Teseu e a única ocorrência de uma variação da forma nominal perfidus fora da seção correspondente à écfrase da tapeçaria.

Embora seja notável a ausência de referências aos aspectos materiais da tapeçaria na descrição desse objeto que nos é apresentada por Catulo, destacam-se ao longo de toda a passagem concernente ao relacionamento de Teseu e Ariadne diversas referências a vestes e outros tipos de tecidos, as quais emolduram não apenas o desespero de Ariadne, esquecida do próprio decoro em meio a seu sofrimento, sem se preocupar com sua nudez e com as vestes levadas pelas ondas, mas também provocam a morte de Egeu por conta do esquecimento de Teseu, que não se lembra de recolher as velas tingidas com púrpura, tal como a própria tapeçaria, e içar as velas brancas, e, em sua forma mais tênue, um simples fio, representam tanto uma esperança de retorno àquele que adentrou o labirinto quanto o prenúncio do desespero de Ariadne. O uso desse vocabulário não se restringe à narrativa acerca de Ariadne e Teseu ou à descrição da manta, mas se prolonga pelos versos seguintes na descrição das vestimentas das Parcas e em sua arte de tecer o fio do destino. ${ }^{105}$

Nas últimas décadas, a presença desse vocabulário relacionado a tecidos e à própria arte de tecer tem sido identificada como uma espécie de tema dentro do poema, tema que estaria diretamente relacionado aos atos de cantar, falar e compor, o que se torna mais explícito na apresentação do canto das Parcas, onde o que é tecido e o que é cantado se unem

${ }^{101}$ Catull., 64.323-81.

${ }^{102}$ Catull., 64.198.

${ }^{103}$ Catull., 64.306.

${ }^{104}$ Catull., 64.322.

${ }^{105}$ Catull., 64.50: uestis; 63: subtilem [... $]$ mitram; 64: leui uelatum [...] amictu; 65: tereti strophio; 68: mitrae [...] fluitantis amictus; 113: tenui [...] filo; 129: mollia [...] tegmina; 163: purpureaue [...] ueste; 174: funem; 225: infecta [...] lintea; 227: carbasus; 234: funestam [...] uestem; 235: candidaque [...] uela; 243: infecti [...] lintea ueli; 265: uestis; 266: amictu; 307: uestis; 309: uittae: 310: carpebant; 311-19: descrição da arte das Parcas; 320: pellentes uellera; 377: filo. 
e se apresentam como uma única peça de arte composta em versos. ${ }^{106}$ Ao longo de grande parte desta composição as percepções do que é visto e do que ouvido se misturam, de modo que a estrutura do próprio carmen 64 também pode ser entendida como uma uestis, como um tecido, em cuja tessitura imagens variadas são interligadas. Se considerarmos o encadeamento das histórias como costuradas pelo poeta, sua audiência parece ser guiada através desses versos por uma espécie de fio de Ariadne, o qual, ao invés de conduzir seu público até os votos conjugais auspiciosos que seriam idealmente endereçados a Peleu e Tétis no dia de sua união, desvia-se dessa imagem, apresentando-nos detalhes sobre uma outra união mitológica no centro desse labirinto, e conduz o leitor/ouvinte de volta à realidade através dos versos moralizantes que encerram o poema. ${ }^{107}$

\section{REFERÊNCIAS}

Arcellaschi, A. 1990. Médée dans le théâtre latin d’ Ennius à Sénèque. Roma: École Française de Rome.

Armstrong, R. 2006. Cretan women: Pasiphae, Ariadne, and Phaedra in latin poetry. Oxford: Oxford University Press.

Auhagen, U. 2000. "Monologe bei Ennius und Catull". In Dramatische Wäldchen: Festschrift für Eckard Lefèvre zum 65, hrsg. E. Stärk et G. Vogt-Spira, 173-87. Geburtstag, Hildesheim: Georg Olms.

Boedeker, D. 1997. "Becoming Medea: Assimilation in Euripides." In Medea: Essays on Medea in myth, literature, philosophy, and art, edited by J. J. Clauss et S. I. Johnston, 127-148. Princeton: Princeton University Press.

Bouvier, D. 2002. "L' Ordre de la Lyre: Le Héros et l' Histoire des Ancêtres". In Le sceptre et la lyre: L' Iliade ou les héros de la mémoire, 313-55. Grenoble: Editions Jérome Millon.

Cairns, F. 1984. "The Nereids of Catullus 64.12-23b." GB 11: 95-101.

Calame, C. 1990. Thésée et l' imaginaire athénien: Légende et culte en Grèce antique. Lausanne: Editions Payot.

Clausen, W. 2002. Virgil's Aeneid: Decorum, allusion, and ideology. München et Leipzig: K. G. Saur.

Contiades-Tsitsoni, E. 1991. Hymenaios und Epithalamion: Das Hochzeitslied in der frühgriechischen Lyrik. Stuttgart: B. G. Teubner.

Curran, L.C. 1969. "Catullus 64 and the heroic age". In YCS 21: Studies in latin poetry, edited by C.M. Dawson and T. Cole. Cambridge: Cambridge University Press.

${ }^{106}$ Acerca do emprego de imagens têxteis ao longo do carmen 64, ver Laird 1993; Rees 1994, 86 ss.; Gaisser 1995, 610 ss.; Ruiz 1997, 85; Scheid et Svenbro 2003; Robinson 2006; Sklenár 2006.

${ }^{107}$ Catull., 64.384-408. 
DeBrohun, J.B. 1999. "Ariadne and the whirlwind of fates: Figures of confusion in Catullus 64.149-57". CPh 94:419-30.

Derouxn, C. 1966. "Some remarks on the handling of ekphrasis in Catullus 64." In Studies in latin literature and roman history VI, edited by C. Derouxn, 247-58. Bruxelles, Latomus.

Diez del Corral Corredoira, P. 2005. “'El Rapto': ¿Una Forma de Amor? Una interpretación de las imagines de persecución y rapto de Dioniso y Ariadna." Gallaecia 24:75-97.

Diez del Corral Corredoira, P. 2007. Esposa y amante de Dioniso. Tesis de Doctorado. Universidad de Santiago de Compostela.

Eidinow, J. S. C. 2003. "Dido, Aeneas, and Iulus: Heirship and obligation in 'Aeneid' 4". CQ 53: 260-7.

Elsner, J. 2007. "Viewing Ariadne: From Ekphrasis to Wall Painting in the Roman World." CPh 52.

Erdmann, W. 1934. Die Ehe im alten Griechenland. München: Beck.

Finley, M.I. 1955. "Marriage, Sale and Gift in the Homeric World". Revue Internationale des Droit de l'Antiquité 3(2):167-94.

Fitzgerald, W. 1995. Catullan provocations: Lyric poetry and the drama of position. Berkeley, Los Angeles et London: University of California Press.

Forsyth, P. Y. 1980. "Catullus 64: Dionysus reconsidered". In Studies in latin literature and roman history II, edited by C. Deroux, 101-3. Bruxelles: Latomus.

Gaisser, J.H. 1995. "Threads in the labyrinth: Competing views and voices in Catullus 64." AJPh 116.

Gallo, A. 1988. "Le pitture rappresentanti Arianna abbandonata in ambiente pompeiano." RSP 2:57-80.

Gernet, L. 1953. "Mariages de tyrans". In Hommage à Lucien Febvre: Éventail de l'histoire vivante offert par l' amitié d' historiens, linguistes, géographes, économistes, sociologues, ethnologues II, 41-53. Paris: Armand Colin.

Giangrande, G. 1977. "Catullus 64". LCM 2: 230-1.

Hersch, K. H. 2010. The roman wedding: Ritual and meaning in antiquity. Cambridge: Cambridge University Press.

Horsfall, N. M. 1990. "Dido in the light of history". In Oxford readings in Vergil's Aeneid, edited by S. J. Harrison, 127-144. Oxford: Oxford University Press.

Hunter, R.L. 1988. "'Short on heroics': Jason in the Argonautica". CQ 38.

Kinsey, T.E. 1965. "Irony and structure in Catullus 64." Latomus 24: 911-31.

Klingner, F. 1964. "Catulls Peleus-Epos", SBAW [Phil.] VI, 1956 = Studien zur griechischen und römischen Literatur. Zürich et Stuttgart, Artemis Verlag

Knopp, S. E. 1976. "Catullus 64 and the conflict between Amores and Virtutes." CPh 71:207-13.

Köhn, S. 1999. Ariadne auf Naxos: Rezeption und Motivgeschichte von der Antike bis 1600. München: Herbert Utz Verlag.

Konstan, D. 1977. Catullus' indictment of Rome: The meaning of Catullus 64. Amsterdam: Adolf M. Hakkert.

Kroll, W. 1960. C. Valerius Catullus. Stuttgart: Teubner.

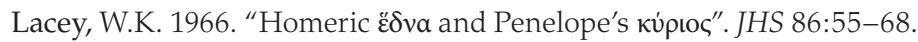

Laird, A. 1993. "Sounding out ecphrasis: Art and text in Catullus 64". JRS 83:18-30. 
Mastronarde, D. J. 2006. Euripides: Medea. Cambridge: Cambridge University Press. Mills, S. 1997. Theseus, tragedy and the athenian empire. Oxford: Clarendon Press.

Moreau, A. 1994. Le mythe de Jason et Médée: Le va-nu-pied et la sorcière. Paris: Les Belles Lettres.

Morris, I. 1986. "The Use and Abuse of Homer". CA 5: 81-138.

Morwood, J. 1999. "Catullus 64, Medea, and the François Vase." GER 46:221-31.

Mynors, R.A.B. 1989. C. Valerii Catulli carmina. Oxford: Clarendon Press.

O'Hara, J. J. 1990. “The significance of Vergil's Acidalia Mater and Venus Erycina in Catullus and Ovid." HSCPh 93.

Oakley, J.H.; Sinos, R.H. 1993. The wedding in ancient Athens. London et Madison: The University of Wisconsin Press.

Oliva Neto, J.A. 1996. O livro de Catulo. São Paulo: EDUSP.

Oswald, R. 1998. "Hochzeitsbräuche und -ritual". DNP 5:649-56.

Pease, A.S. 1967. Publi Vergili Maronis Aeneidos: Liber quartus. Darmstadt: Wissenschaftliche Buchgesellschaft.

Pereira, M. H. da R. 1980. Estudos de história da cultura clássica II: Cultura romana. Lisboa: Fundação Calouste Gulbekian.

Perysinakis, I. N. 1991. "Penelope's EEANA again". CQ 41: 297-302.

Putnam, M.C.J. 1961. "The Art of Catullus 64." HSCPh 65.

Rees, R. 1994. "Common Sense in Catullus 64". AJPh 115.

Robinson, T. J. 2006. "Under the cover of epic: Pretexts, subtexts and textiles in Catullus' carmen 64." Ramus 35:29-62.

Rodrigues Jr., F. 2005. Epopéia e poesia alexandrina: Estudo e tradução do canto III dos Argonáutica de Apolônio Ródio. Dissertação de Mestrado. Universidade de São Paulo.

Rudd, N. 1990. "Dido's culpa". In Oxford readings in Vergil's Aeneid, edited by S. J. Harrison, 145-66. Oxford: Oxford University Press.

Ruiz Sánchez, M. 1997. "Formal technique and epithalamial setting in the song of the parcae." AJPh 118.

Scheid, J.; Svenbro, J. 2003. "Les Noces de Pélée et de Thétis: Couvertures Nuptiales à Rome". In Le métier de Zeus: Mythe du tissage et du tissu dans le monde grécoromain, 73-89. Paris: Editions Errance.

Sklenár, R. 2006. "How to dress (for) an epyllion: The fabrics of Catullus 64." Hermes 134:385-97.

Snodgrass, A.M. 1974. "An historical homeric society". JHS 94.

Stoevesandt, M. 1994-1995. "Catull 64 und die Ilias: Das Peleus-Thetis-Epyllion im Lichte der neueren Homer-Forschung." WJA 20:167-205.

Thomson, D.F.S. 2003. Catullus. Edited with a textual and interpretative commentary. Toronto: University of Toronto Press.

Treggiari, S. 1991. Roman marriage. Iusti coniuges from the time of Cicero to the time of Ulpian. Oxford: Clarendon Press.

Trimble, G. 2009. "Catullus and the tragedy of Ariadne." Mosaïque 1:1-19.

Vernant, J.P. 1992. "O casamento". In Mito e sociedade na Grécia antiga, 48-70. Tradução de Myriam Campello. Rio de Janeiro: Editora da Universidade de Brasília \& José Olímpio Editora. 
Walker, H.J. 1995. Theseus and Athens. New York et Oxford: Oxford University Press. Webster, T.B.L. 1966. "The myth of Ariadne from Homer to Catullus." GER 13:22-31 Williams, G. 1968. Tradition and originality in roman poetry. Oxford: Clarendon Press. Wiseman, T. P. 1977. "Catullus' Iacchus and Ariadne". LCM 2:177-80.

Wiseman, T. P. 1978. "Catullus 64 again". LCM 3:21-2.

Wolff, J. 1944. "Marriage law and family organization in ancient Athens: A study on the interrelation of public and private in the greek city". Traditio 2:43-95.

Title. The myth of Ariadne in Catullus' carmen 64.

Abstract. This paper aims to analyse the ekphrastic narrative about Ariadne found in Catullus' carmen 64 and to show how the poet interweaves myths about Ariadne and Theseus with the celebration of the marriage of Thetis and Peleus in the composition of the poem.

Keywords. Catullus; Ariadne; ekphrasis; marriage; weaving. 